\title{
Research on the Network Platform Establishment of Scientific Archives Management
}

\author{
Deming Fan ${ }^{1,}$, , Yang Zuo ${ }^{2, b}$, Yuxin Tian ${ }^{3, c}$ \\ ${ }^{1,2,3}$ Research Department, Shandong Institute of Business and Technology, YanTai, China \\ afandm@sdibt.edu.cn, bsdibtzy@163.com, 'tianyuxin2006@sina.com
}

\begin{abstract}
Keywords: Scientific archives, Infomationize, Countermeasure
\end{abstract}
\begin{abstract}
With the widespread use of computer and network technology, informatization has become an irresistible trend. There are some methods of updating the management of scientific archives in college, for purpose to improve the openness to scientific archives and promote information sharing, provide the roundly, real-time and accuratly scientific information for managers, which is the key point of the scientific research nowadays.
\end{abstract}

\section{Definition of the Management on Scientific Archives}

The management of scientific archives in college is the files with certain technoligical value for inquire and utilize which were formed in the acitivities such as education and research(incuiding resources of charts, images, objects and ducuments which formed inscientific research project, scientific achievements, academic activities) [1]. An integrated scientific archives not only write down the process of the item in veritable, intergral and accurate way, but matters in its transfomation and generalization. The major task of scientific research is file the recoeds properly, protect and manage them scientifically, sevre the educate and research to its fullest potential.

\section{Current Situation and Problems of Management on Scientific Archives}

First of all, being lack of macroscopically scheme and management, working seperately without considering of the whole interests is the major problem. The scientific archives of college are dispersed in three parts, one is controlled by researchers, the second is administrative staffs in different schools, the last part lies in the hand of depart of science and technology of colleges. The unreasonable divide of work resulted in indeterminate distribution, even no distribution, which certainly influenced the file negatively.

Secondly, technological process of management is antiquated. The sign and issue, deliverance, transaction, file, management, borrowing, register, identify, statistics and other works are conducted in traditional flow. It is obvious that the work by hands in most circumstances is difficult to the inquirements in collecting, processing and utilizing. [2]

Then, the management condition and equipment are poor. Scientific research files are tend to be generally managed with other kinds of archives management, and there are rare archives of science and technology. Some of the safekeeping conditions can't meet the needs of scientific researches. Most scientific research files have not been standardized settled, classification is not clear, group volume chaos, uncomplete, all of them resulted that it is not conducive to find and use. In modern information age like today, the real form of electronic files is rare and they are saved in paper, is not conducive to query and utilization of network..

At last, the system is not sound enough. Although universities formulated scientific research archives management system correspondly, there is still no centralized and unified management system. There is a difference between scientific research archives management system between the college and secondary schools, which makes scientific research archives filing work lack of system and integrity. The relevant work of scientific research stresses the rights and obligations of the managers, but does not emphasize the corrective action and disciplinary measures when there are problems, which makes the scientific research management in the process of the lack of effective 
means. In addition, the lack of effective scientific performance appraisal system for managers makes the scientific research archival management in colleges and universities authority being weaken continuously.

\section{The Necessity of the Network Platform Establishment of Management of Scientific Archives}

Traditional scientific research archives management work mainly using artificial archive entity for the process of collecting, sorting, preservation and utilization, which are all save in paper, with consuming enormous manpower and material resources, and processed slowly. In information age, forming real electronic archives with using the database and network technology, improving the file storage the using of archives information and query greatly, which benefits to save human and social resources. Scientific research files management informatization, is the basic requirement to adapt to the progress of science and technology, archives management to the inevitable trend of modernization[3].

The research process can also carry out network query, release information, download materials, so as to better realize the online tracking service, promote the management of division of Labour intensively, accelerate management information transmission and feedback process, give full play to the value of scientific research archives information resources, realize scientific research archives information resources sharing[4].

\section{Countermeasure on the Network Platform Estabilshment of Management of Scientific Archives}

Scientific research archives informatization construction is a delicate and complex task, with a certain professional target. It cannot be done overnight, but needs to have a overall, macroscopic planning and deployment. The informationization construction is an overall consideration, step-by-step implementation, a whole advancement.

Changing concept on the network platform estabilshment of management of scientific archives. The first is to change the idea of school leaders. Scientific research work, on the basis of further emphasize the management of scientific research archives, attaches great importance to the scientific research archives informatization, and realize scientific research archives informatization is an important approach to improve the service level of archives, to speed up the informatization construction of scientific research archives work..

Secondly, to change the idea of scientific researchers. Through various publicity to strengthen the scientific researchers file consciousness, get the support and cooperation of scientific researchers and make it active, timely submitted to the scientific research archives, particularly with writing material matching electronic archives. Want to let everybody to realize the value of archives resources, thereby stimulating the enthusiasm of their collection, handing over archives.

Thirdly, to change the concept of the staffs inscientific research management department, scientific research management departments should actively create conditions to carry out services. Archivists should be ready to provide the file using the work at the same time, take the initiative to go deep into the various departments, especially in scientific research, propaganda and filing scope and requirements, understand a line of scientific research work to carry out the situation, solve their problems in the process of collecting files, at the same time for teachers to consult relevant scientific research archives to provide timely and convenient services, make teachers feel that functions of the scientific research files exist to be both safe and convenient, to ensure that scientific research archives management work is turnning to a more standardization, streamline, efficiency one.

The establishment and improvement of the scientific research archival management informationization environment. The first thing is to the develop the scientific research archives resources acquisition system, and provide effective, standardized, feasible acquisition means and technology, formed the perfect digital collection standard and security system. Scientific research archives informatization shall be equipped with computer, scanner, digital carrier network 
environment and other professional equipments.

Secondly, to develop scientific research archives management information system and improve information gathering information of sorting and search, by using of the efficiency and accuracy of the use of information, realizing the automation of scientific research archives processing. Development of scientific research archives management information system, is starting from the content, process of scientific research files management automationly.

Thirdly, to develop integrated service management system, and expand the application areas of information and content, by providing special retrieval, SDI tracking service, scientific and technological achievements query, literature research, preparation of project database and other comprehensive services. To develop a service platform for notice, intercourse, online consulting, to carry out the remote interactive services, provides the user with a text, voice, image and other multimedia information, which make the resource sharing become true.

Finally, the implementation of archives information management network, use of modern network communication technology will be the university scientific research archives information retrieval system and library information retrieval system integration into the information network, mutual communication of information and information query, constitute a complete network of university's scientific research information management center, can make full development and utilization of archives information, maximum limit satisfy the management of colleges and universities, teaching, scientific research and product development needs[5].

To cultivate scientific research archives management talents. Talents is the guarantee to the sustainable development of the scientific research archival management in colleges and universities, and the key of information construction. What Scientific research archives management of colleges and universities information construction need is a large number of both have rich experience in scientific research archives in colleges and universities, and can master the modern information technology talents, a team that devoted themselves to the university scientific research archives and master the modern information technology development principles, methods, resources construction team and the information infrastructure management[6].

First of all, to strengthen the self-building of scientific research archives managers,and improve the file managers' service quality, to establish an open service consciousness and the concept of service for scientific research, technology innovation and social development to adapt to the new requirements, on the one hand, have the profound theory of archival science, on the other hand, it pays attention to scientific research management archives personnel training and furthers education, encourages them to strengthen business study[7].

Secondly, we should strengthen the study of the theory of modern information management, and pay attention to scientific research management archives personnel training and further education, offered the opportunity to let them take part in various learning training, to grasp the newest trend of archives work. Through learning, they can broaden horizons, enhance understanding, and deepen their understanding of archives information construction, to contribute to scientific research archives informatization construction more effectively.

\section{References}

[1] Yanling Nong. Research of the archives management of university scientific research project, J. Chinese Science \& Technology Industry, 2009( 7) : 83-85.

[2] Rui Zhang, Chang Su, Chengyu Sun, Exploration of the informatization of scientific research management in Colleges and Universities, J. Journal of Jilin Institute of Chemical Technology, 2010,27( 6) : 33-35.

[3] Yingchao Guan, Lan Chen, Shibin $\mathrm{Xu}$, Discussion on the scientific research management innovation in Universities under the new situation, J. Journal of Sichuan Normal University, 2010,4( 33) : 568-571. 
[4] Lin Wang, The management mode of archives in Colleges and Universities, J. Electromechanical transports archives,2009,(6):.40-41.

[5] Yuan Tian, Some reflections on the standardization of archives management, J. Human resources development,2009,(10):23-24.

[6] Yabo Li, Chunbo Dai, Analysis of university archives information construction, J. Heilongjiang archives,2004,(11):27.

[7] Yanqin Wang, Development and utilization of archival information resources of scientific research[J]. Theoretical exploration, 2004(5):34. 